\title{
Highly regioselective di-tert-amylation of naphthalene over reusable H-mordenite zeolite
}

\author{
Keith Smith,* Alaa K. H. Al-Khalaf, Gamal A. El-Hiti*† and Samuel Pattisson
}

School of Chemistry, Cardiff University, Main Building, Park Place, Cardiff, UK, CF10 $3 A T$

E-mail: smithk13@cardiff.ac.uk, el-hitiga@cardiff.ac.uk; Fax:+44(0)2920870600;Tel: $+44(0) 2920870600$

$\uparrow$ Permanent address: Chemistry Department, Faculty of Science, Tanta University, Tanta 31527, Egypt

Highly regioselective di-tert-amylation of naphthalene using different alcohols can be achieved over a H-mordenite (HM) zeolite. For example, the tert-amylation of naphthalene using tert-amyl alcohol in cyclohexane over $\mathrm{HM}(\mathrm{Si} / \mathrm{Al}=10)$ zeolite has been optimised to give a 70\% yield of 2,6-dialkylnaphthalenes, of which 2,6-di-tertamylnaphthalene was produced in $46 \%$ yield along with 2-tert-amyl-6-tertbutylnaphthalene (23\%) and 2,6-di-tert-butylnaphthalene (1\%). This has been achieved by varying the reaction time, temperature, pressure and amounts of tert-amyl alcohol and zeolite. No 2,7-dialkylnaphathalenes were seen under the conditions tried. The zeolites can be easily regenerated by heating and then reused.

\section{Introduction}

There is considerable interest in the use of zeolites to control alkylation of naphthalene, ${ }^{1-14}$ primarily as a result of the commercial importance of 2,6-dimethylnaphthalene (DMN), a precursor of naphthalene-2,6-dicarboxylic acid (NDA), which is needed for production of poly(ethylene naphthalate) (PEN). Current methods for the production of DMN are cumbersome and low yielding and require separation of complex mixtures including isomers, ${ }^{15}$ followed by extensive recycling, in 
order to provide a reasonable quantity of product. Consequently, utilisation of PEN is limited by the commercial availability and cost of DMN. A greener method for production of DMN or an alternative PEN precursor, involving fewer processes, higher yields of desired products, and less need for separation and recycling, is much needed.

A convenient process for preparation of DMN would be selective dimethylation of naphthalene. Unfortunately, in addition to the usual problems of polyalkylation, the $\beta$-positions of naphthalene are less reactive than the $\alpha$-positions and there are 10 possible isomeric dimethylnaphthalenes, so simple double methylation of naphthalene is not easy to control to give the specific compound required. Mixtures of isomers are produced and require separation. ${ }^{16}$ Since the 2,6-disubstituted compounds are the most "linear" isomers, zeolites offer a possible way to favour such products.

It is well recognised that zeolites and other solid catalysts can play an important role in the development of greener organic syntheses through their abilities to act as recyclable heterogeneous catalysts, support reagents, entrain by-products, avoid aqueous work-ups and enhance product selectivities. ${ }^{17-22}$ For example, we have shown that zeolites or other solids can have advantages in nitration, ${ }^{23-28}$ bromination, ${ }^{29}$ chlorination, ${ }^{30}$ methanesulfonylation $^{31}$ and acylation ${ }^{32,33}$ as well as alkylation ${ }^{34,35}$ of aromatic compounds.

Indeed, a degree of $\beta$-selectivity in dimethylation of naphthalene has been achieved over zeolite HZSM-5, whereas non-selective methylation was seen over the larger pore H-mordenite (HM) and HY zeolites. ${ }^{36}$ However, even using HZSM-5 a poor yield of the 2,6-isomer was obtained and the ratio of 2,6/2,7 isomers was approximately 1 .

Since other 2,6-dialkylnaphthalenes can in principle also be oxidised to NDA, attempts to gain greater control have been extended to use of alternative alkylating agents. iso-Propylation of naphthalene with propene, ${ }^{37}$ iso-propyl alcohol ${ }^{38-42}$ and iso-propyl bromide ${ }^{43}$ has been studied using a variety of zeolites and $\beta, \beta$-selectivities of over $75 \%$, with a 2,6/2,7 ratio of approximately 2 , have been reported using H-mordenite. ${ }^{44}$ The best iso-propylation procedure gave 2,6-di-iso-propylnaphthalene in $54 \%$ yield, along with $14 \%$ of 2,7-di-iso-propylnaphthalene, i.e. a 2,6/2,7 ratio of $4 .{ }^{44}$ The best reported cyclohexylation makes use of HY zeolite, and results in the corresponding 
2,6-dicyclohexylnaphthalene in $19 \%$ yield, along with $17 \%$ of 2,7-dicyclohexylnaphthalene, i.e. a 2,6/2,7 ratio of 1.1. ${ }^{45}$ The same authors also reported tert-butylation to give a $23 \%$ yield of 2,6-di-tert-butylnaphthalene, with around $4 \%$ of 2,7-di-tert-butylnaphthalene, i.e. a 2,6/2,7 ratio of 5.9, with the added advantage of easy separation of the 2,6-isomer by crystallisation. ${ }^{46,47}$

By studying the above reaction in more detail, we have previously shown that highly regioselective di-tert-butylation of naphthalene could be achieved over zeolite H-mordenite using tert-butyl alcohol as the alkylating agent under autoclave conditions. ${ }^{34,35}$ The process was a convenient, high yielding and highly regioselective method for the synthesis of 2,6-di-tert-butylnaphthalene, which was produced in $60 \%$ yield, along with only $1 \%$ of 2,7-di-tert-butylnaphthalene, i.e. a 2,6/2,7 ratio of over $50 .{ }^{34,35}$ Although this method is easily the most selective yet discovered for production of a 2,6-dialkylnaphthalene, it may be difficult to oxidise the tert-butyl group to a carboxyl group. ${ }^{48}$ Therefore, we were interested to see if a process could be devised that would give a 2,6-dialkylnaphthalene in which the alkyl groups could be cracked to an alkyl group that could be oxidised relatively easily to a carboxyl group. ${ }^{49}$ We decided to undertake a study of dialkylation of naphthalene using various alcohols over different zeolites in a solvent under autoclave conditions similar to those used successfully in tert-butylation of naphthalene. ${ }^{34,35}$ We now report the details of such a study.

\section{Results and discussion}

We have shown previously that the best results obtained for the tert-butylation of naphthalene using tert-butyl alcohol under autoclave conditions involved use of cyclohexane as a solvent and $\mathrm{HM}(\mathrm{Si} / \mathrm{Al}=10)$ zeolite as a catalyst at $180{ }^{\circ} \mathrm{C} .{ }^{34,35}$ Initially, a range of different commercial zeolites was screened for efficiency in the tert-amylation of naphthalene $(\mathbf{1} ; 10 \mathrm{mmol})$ using tert-amyl alcohol under self generated pressure (50$150 \mathrm{psi}$ ) in cyclohexane, under conditions as close as possible to those used in the tert-butylation reactions. ${ }^{34,35}$ The properties of the zeolites used in this study are recorded in Table 1. The zeolites were calcined prior to use, which would have converted any ammonium forms into the corresponding proton forms. The major products of the tert-amylation reaction were 2-tert-amylnaphthalene (2), 2-tert-butylnaphthalene (3), 
2,6-di-tert-amylnaphthalene (4), 2-tert-amyl-6-tert-butylnaphthalene (5), and 2,6-di-tertbutylnaphthalene (6) (Scheme 1) and the yields obtained are given in Table 2. Several other minor peaks were seen in the GC, some of which were shown (by conducting an experiment in the absence of naphthalene) to arise from the decomposition of tert-amyl alcohol under the reaction conditions.

Table 1 Typical properties of the commercial zeolites ${ }^{2,50}$

\begin{tabular}{|c|c|c|c|c|c|c|c|}
\hline Zeolite & Product code & $\begin{array}{l}\mathrm{Si} / \mathrm{Al} \\
\text { ratio }\end{array}$ & $\begin{array}{l}\text { Nominal } \\
\text { cation } \\
\text { form }\end{array}$ & $\begin{array}{l}\mathrm{Na}_{2} \mathrm{O} \\
(\mathrm{wt} \%)\end{array}$ & $\begin{array}{l}\text { Pore } \\
\text { volume } \\
\left(\AA^{3}\right)^{a}\end{array}$ & $\begin{array}{l}\text { Pore } \\
\text { diameter } \\
(\AA)\end{array}$ & $\begin{array}{l}\text { Surface } \\
\text { area } \\
\left(\mathrm{m}^{2} / \mathrm{g}\right)\end{array}$ \\
\hline HY & CBV 720 & 15 & $\mathrm{H}$ & 0.03 & 730 & $7.4 \times 7.4$ & 780 \\
\hline $\mathrm{H} \beta$ & CP 811E-150 & 75 & $\mathrm{NH}_{4}$ & 0.05 & 150 & $\begin{array}{l}6.6 \times 7.7 \& \\
5.5 \times 5.6\end{array}$ & 720 \\
\hline HM & CBV 21A & 10 & $\mathrm{NH}_{4}$ & 0.08 & 150 & $6.5 \times 7.0$ & 500 \\
\hline $\mathrm{HM}$ & CBV 90A & 45 & $\mathrm{H}$ & 0.05 & 150 & $6.5 \times 7.0$ & 500 \\
\hline HZSM-5 & CBV 3024E & 15 & $\mathrm{NH}_{4}$ & 0.05 & 130 & $\begin{array}{l}5.3 \times 5.6 \& \\
5.1 \times 5.5\end{array}$ & 400 \\
\hline
\end{tabular}

${ }^{a}$ Pore volume was calculated using the formula: $=4 / 3 \pi\left(D_{i} / 2\right)^{3}$, where $D_{i}$ represents the maximum included sphere diameter $(\AA) .{ }^{50}$

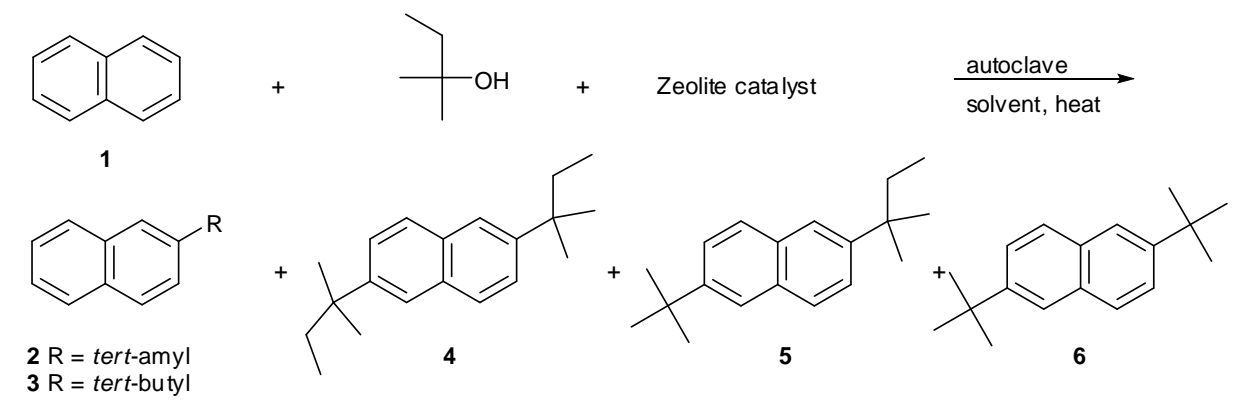

Scheme 1 tert-Amylation of naphthalene (1) using tert-amyl alcohol over zeolite catalysts under autoclave conditions 
Table 2 tert-Amylation of naphthalene (1) using tert-amyl alcohol over various zeolites under autoclave conditions according to Scheme $1^{a}$

\begin{tabular}{|c|c|c|c|c|c|c|}
\hline \multirow[t]{2}{*}{ Zeolite } & \multicolumn{6}{|c|}{ Yields $(\%)^{b}$} \\
\hline & 1 & 2 & 3 & 4 & 5 & 6 \\
\hline $\mathrm{HM}(\mathrm{Si} / \mathrm{Al}=10)$ & 17 & 60 & 0.5 & 16 & 6 & 0.5 \\
\hline $\mathrm{HM}(\mathrm{Si} / \mathrm{Al}=45)$ & 53 & 31 & 2.5 & 8 & 3 & 0.5 \\
\hline $\mathrm{H} \beta(\mathrm{Si} / \mathrm{Al}=75)$ & 32 & 57 & 1.5 & 1 & 4 & 1.5 \\
\hline $\mathrm{HY}(\mathrm{Si} / \mathrm{Al}=15)^{c}$ & 6 & 10 & 1 & 1 & 1 & 2 \\
\hline $\operatorname{HZSM}-5(\mathrm{Si} / \mathrm{Al}=15)$ & 85 & 13 & 1.5 & 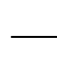 & - & - \\
\hline
\end{tabular}

${ }^{a} 6 \mathrm{~h}$ stirred autoclave reaction under self generated pressure at $180{ }^{\circ} \mathrm{C}$; zeolite catalyst $(4.0 \mathrm{~g})$, cyclohexane $(50 \mathrm{~mL})$, naphthalene $(1.28 \mathrm{~g} ; 10 \mathrm{mmol})$ and tert-amyl alcohol $(1.76$ g; $20 \mathrm{mmol}$ ). ${ }^{b}$ Determined by GC based on the response factors of $\mathbf{1}, \mathbf{2}$ and 4 . It was assumed that the response factor of $\mathbf{3}$ is the same as for $\mathbf{2}$ and those of $\mathbf{5}$ and $\mathbf{6}$ are the same as for 4 . Numbers expressed as percentages have been rounded to the nearest whole number, except for yields below 3\%, which have been rounded to the nearest $0.5 \%$. ${ }^{c}$ Various other alkylated naphthalenes were produced.

The results reported in Table 2 indicated that $\mathrm{HY}(\mathrm{Si} / \mathrm{Al}=15)$ was not selective and produced various other alkylated naphthalenes. Zeolite HZSM-5 gave 2-tert-amylnaphthalene (2) in $13 \%$ yield along with 2-tert-butylnaphthalene $(3 ; 1.5 \%)$ with low conversion (15\%). No dialkylnaphthalenes were formed, presumably because the pores were too small to allow dialkylation to occur. The other zeolites tried were more reactive and more regioselective to produce 2,6-dialkylnapthalenes 4-6. In the case of the HM zeolites no 2,7-dialkyl isomers were observed. Zeolite $\mathrm{HM}(\mathrm{Si} / \mathrm{Al}=10)$ was found to be more reactive than zeolite $\mathrm{HM}(\mathrm{Si} / \mathrm{Al}=45)$. With $\mathrm{HM}(\mathrm{Si} / \mathrm{Al}=10)$, a naphthalene conversion of $83 \%$ and a $22.5 \%$ yield of 2,6-dialkyl products, of which 2,6-di-tert-amylnapthalene 4 represented an overall $16 \%$ yield, were observed. 2-tert-Amylnaphthalene (2) was found to be the major product, produced in $60 \%$ yield, while, 2-tert-butylnaphthalene (3) was present in very low yield. Therefore, we undertook a more detailed study of the reaction with $\mathrm{HM}(\mathrm{Si} / \mathrm{Al}=10)$ as activator in the hope of enhancing the conversion of $\mathbf{1}$ and $\mathbf{2}$ to $\mathbf{4}$.

Compounds 3, 5 and $\mathbf{6}$ were presumably obtained as a result of generation of tert-butyl carbocation through breakdown of tert-amyl cation produced from tert-amyl alcohol in the presence of acidic zeolite. tert-Amyl derivatives were produced in a similar way during reactions of naphthalene with tert-butanol, ${ }^{34}$ indicating that interconversion of 
tert-butyl and tert-amyl cations occurs under the conditions (Scheme 2). However, the yields of tert-butyl derivatives in reactions involving tert-amyl alcohol were much greater than the yields of the corresponding tert-amyl compounds had been in reactions involving tert-butyl alcohol. This presumably reflects easier diffusion of tert-butyl derivatives than tert-amyl ones within the zeolite pores, a phenomenon that may also be responsible for the greater 2,6-selectivity exhibited in reactions involving tert-amyl alcohol.

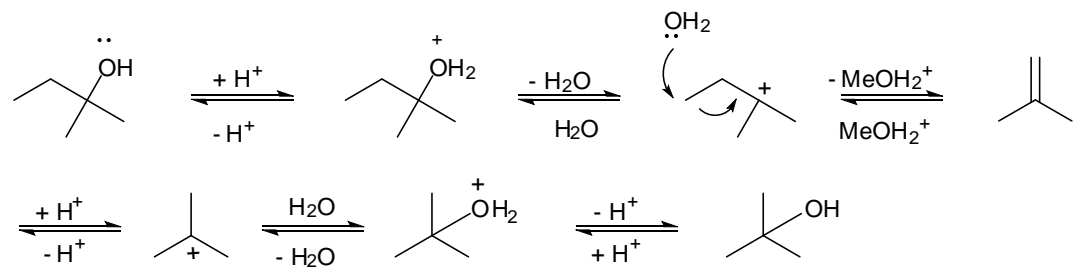

Scheme 2 Interconversion of tert-amyl and tert-butyl cations over zeolite

In order to test the effect of solvent in the reaction, reactions were carried out in several different solvents for $6 \mathrm{~h}$ at $180{ }^{\circ} \mathrm{C}$ in an autoclave. The results are recorded in Table 3.

Table 3 Effect of solvent in the tert-amylation of naphthalene (1) using tert-amyl alcohol over $\mathrm{HM}(\mathrm{Si} / \mathrm{Al}=10)$ under autoclave conditions according to Scheme $1^{a}$

\begin{tabular}{lllllll}
\hline Solvent & \multicolumn{7}{c}{ Yields $(\%)^{b}$} \\
\cline { 2 - 7 } & $\mathbf{1}$ & $\mathbf{2}$ & $\mathbf{3}$ & $\mathbf{4}$ & $\mathbf{5}$ & $\mathbf{6}$ \\
\hline Cyclohexane & 17 & 60 & 0.5 & 16 & 6 & 0.5 \\
iso-Pentane & 95 & 3 & 2 & - & - & - \\
Heptane & 65 & 23 & 1.5 & 5 & 2 & - \\
Dichloromethane & 89 & 7 & 0.5 & 1 & - & - \\
1,2-Dichloroethane & 54 & 34 & 1 & 6 & 4 & - \\
Tetrachloroethene & 85 & 9 & - & 1 & - & - \\
${ }^{6}$ 6 h stirred autoclave reaction under self generated pressure at 180 & ${ }^{\circ} \mathrm{C}$; $\mathrm{HM} \mathrm{(Si/Al} \mathrm{=} \mathrm{10;}$ \\
$4.0 \mathrm{~g})$, solvent $(50 \mathrm{~mL})$, naphthalene $(1.28 \mathrm{~g} ; 10$ mmol) and tert-amyl alcohol $(1.76 \mathrm{~g} ; 20$ \\
mmol). ${ }^{b}$ See footnote $b$ to Table 2.
\end{tabular}

With iso-pentane, dichloromethane and tetrachloroethene as the solvents, the reactions were significantly slower than the reactions carried out in other solvents. The yields of 4 and 5 were highest (16 and 6\%, respectively) when the reaction was carried 
out in cyclohexane. It seemed that the best solvent was cyclohexane, which had already been used in the earlier study (Table 2).

Increased pressure could in principle enhance the rate of reaction through forcing hindered reactants into the pores of the zeolite. Our attention was therefore turned to investigation of the effect of pressure on the reaction represented in Scheme 1. Several tert-amylation reactions of naphthalene $(1 ; 10 \mathrm{mmol})$ were carried out using tert-amyl alcohol $(20 \mathrm{mmol})$ over $\mathrm{HM}(\mathrm{Si} / \mathrm{Al}=10 ; 4 \mathrm{~g})$ in cyclohexane $(50 \mathrm{~mL})$ at $180{ }^{\circ} \mathrm{C}$ for $6 \mathrm{~h}$ under various initial external pressures (150-500 psi) of nitrogen gas in an autoclave. However, it was found that when the starting pressure was increased from 150 to $500 \mathrm{psi}$, the conversion and the yield of 4 decreased from 81 to $48 \%$ and from 12 to $3 \%$, respectively. Compound 2 was the major product (31-58\%) in all cases. The ratio of 4:5 appeared to diminish slightly at the higher pressures, but the yield of $\mathbf{6}$ was very low (0.5$1 \%$ ) in all cases. Since applying additional pressure offered no yield enhancement it was decided to use only self-generated pressure for further reactions to try to improve the yield of 4 .

In order to gauge the effect of temperature, the reaction temperature was varied in $10{ }^{\circ} \mathrm{C}$ stages from 140 to $200{ }^{\circ} \mathrm{C}$ over $4.0 \mathrm{~g}$ of $\mathrm{HM}(\mathrm{Si} / \mathrm{Al}=10)$. The results obtained are given in Table 4.

Table 4 Varying the temperature in the tert-amylation of naphthalene (1) using tert-amyl alcohol over $\mathrm{HM}(\mathrm{Si} / \mathrm{Al}=10)$ under autoclave conditions according to Scheme $1^{a}$

\begin{tabular}{lllllll}
\hline T $\left({ }^{\circ} \mathrm{C}\right)$ & \multicolumn{6}{c}{ Yields $(\%)^{b}$} \\
\cline { 2 - 7 } & $\mathbf{1}$ & $\mathbf{2}$ & $\mathbf{3}$ & $\mathbf{4}$ & $\mathbf{5}$ & $\mathbf{6}$ \\
\hline 140 & 95 & 3 & - & - & - & - \\
150 & 87 & 10 & 2 & 1 & - & - \\
160 & 71 & 23 & 3 & 2 & 1 & - \\
170 & 36 & 47 & 3 & 5 & 5 & - \\
180 & 19 & 58 & 0.5 & 12 & 10 & 0.5 \\
190 & 25 & 56 & 0.5 & 10 & 8 & 0.5 \\
200 & 31 & 52 & 1.5 & 8 & 6 & 1 \\
${ }^{a} 6$ h stirred autoclave reaction under self generated pressure; HM (Si/Al $\left.=10 ; 4.0 \mathrm{~g}\right)$, \\
cyclohexane (50 mL), naphthalene $(1.28 \mathrm{~g} ; 10$ mmol) and tert-amyl alcohol $(1.76 \mathrm{~g} ; 20$ \\
mmol). ${ }^{b}$ See footnote $b$ to Table 2.
\end{tabular}


It was found that when the temperature was increased from 140 to $180{ }^{\circ} \mathrm{C}$, the conversion increased from 5 to $81 \%$ and the yield of 4 increased from 0 to $12 \%$. However, when the temperature was increased further to $200{ }^{\circ} \mathrm{C}$, both conversion and yield of 4 were seen to fall, to $69 \%$ and $8 \%$, respectively. In addition, the yield of $\mathbf{5}$ was seen to decrease when the yield of $\mathbf{4}$ decreased at the higher temperatures, but the yield of 6 seemed to increase. However, the maximum yields of 3 and $\mathbf{6}$ were only 3 and 1\%, respectively. It is clear that $\mathbf{2}$ is still the major product in all cases. Therefore, it was decided to standardise the temperature at $180^{\circ} \mathrm{C}$ for further reactions.

We next varied the quantity of $\mathrm{HM}(\mathrm{Si} / \mathrm{Al}=10)$ in stages from 2 to $8 \mathrm{~g}$ under otherwise constant reaction conditions, without any externally applied pressure.

However, varying the amount of zeolite had no consistent effect on the conversion or on the yield of 4 . When the amount of the HM catalyst was $6 \mathrm{~g}$, the conversion of naphthalene, the yield of $\mathbf{4}$ and the selectivity were all relatively high, but the lack of any trend implied that other factors (such as the efficiency of stirring mixtures containing large amounts of solid) might be equally significant and any increase in the yield of 4 would not justify the use of a large quantity of catalyst. Therefore, $4 \mathrm{~g}$ of catalyst was retained for further investigations.

To determine if there was any benefit to be gained by varying the amount of the reagent, the amount of tert-amyl alcohol was varied over $4.0 \mathrm{~g}$ of $\mathrm{HM}$ at $180{ }^{\circ} \mathrm{C}$. The amount of tert-amyl alcohol was increased in stages from 20 to $80 \mathrm{mmol}$. The results obtained are given in Table 5.

It was found that increasing the amount of tert-amyl alcohol up to $40 \mathrm{mmol}$ brought about increases in both the conversion and the yield of $\mathbf{4}$, by 14 and $10 \%$, respectively, perhaps because of the higher concentration of the alkylating agent. However, use of 60 and $80 \mathrm{mmol}$ caused both the conversion and yield of 4 to fall successively, perhaps as a result of deactivation of acidic sites on the zeolite by interaction with the excess alcohol. However, it was interesting to note that the selectivity for production of $\mathbf{4}$ instead of $\mathbf{5}$ was somewhat greater in the presence of a larger quantity of the alcohol. Therefore, it was of interest to investigate the reactions in the presence of different quantities of alcohol over longer reaction periods, which would hopefully lead to higher conversions, while perhaps retaining the greater selectivity. 
Table 5 Varying the quantity of tert-amyl alcohol in the tert-amylation of naphthalene (1) over $\mathrm{HM}(\mathrm{Si} / \mathrm{Al}=10 ; 4.0 \mathrm{~g})$ according to Scheme $1^{a}$

\begin{tabular}{lllllll}
\hline tert-Amyl alcohol (mmol) & \multicolumn{7}{c}{${\text { Yields }(\%)^{b}}^{b}$} \\
\cline { 2 - 7 } & $\mathbf{1}$ & $\mathbf{2}$ & $\mathbf{3}$ & $\mathbf{4}$ & $\mathbf{5}$ & $\mathbf{6}$ \\
\hline 20 & 30 & 52 & 2.5 & 9 & 5 & 1 \\
40 & 16 & 51 & 1.5 & 19 & 11 & 1.5 \\
60 & 21 & 50 & 3 & 14 & 8 & 1 \\
80 & 40 & 49 & 0.5 & 7 & 3 & 0.5
\end{tabular}

${ }^{a} 6 \mathrm{~h}$ stirred autoclave reaction under self generated pressure at $180{ }^{\circ} \mathrm{C} ; \mathrm{HM}(\mathrm{Si} / \mathrm{Al}=10$, $4.0 \mathrm{~g})$, cyclohexane $(50 \mathrm{~mL})$, naphthalene $(1.28 \mathrm{~g} ; 10 \mathrm{mmol})$ and tert-amyl alcohol. ${ }^{b}$ See footnote $b$ to Table 2 .

A series of experiments was conducted in which the duration of the reaction was varied from $1 \mathrm{~h}$ to $12 \mathrm{~h}$ in cyclohexane $(50 \mathrm{~mL})$ while the quantity of tert-amyl alcohol was also varied (20 to $80 \mathrm{mmol}$ for $10 \mathrm{mmol}$ of 1). Because of difficulties associated with representative sampling of heterogeneous reaction mixtures in an autoclave, a separate experiment was conducted for each data point, which could lead to some scatter in the results because of variations in stirring efficiency and other parameters. The results obtained are given in Table 6.

Table 6 Varying the reaction time and quantity of tert-amyl alcohol in the tert-amylation of naphthalene (1) over $\mathrm{HM}(\mathrm{Si} / \mathrm{Al}=10 ; 4.0 \mathrm{~g})$ according to Scheme $1^{a}$

\begin{tabular}{llllllll}
\hline $\begin{array}{l}\text { Time } \\
(\mathrm{h})\end{array}$ & $\begin{array}{l}\text { tert-Amyl alcohol } \\
(\mathrm{mmol})\end{array}$ & $\mathbf{1}$ & $\mathbf{2}$ & $\mathbf{3}$ & $\mathbf{4}$ & $\mathbf{5}$ & $\mathbf{6}$ \\
\hline 1 & 20 & 43 & 47 & - & 6 & 3 & - \\
3 & 20 & 34 & 52 & 0.5 & 9 & 4 & 0.5 \\
6 & 20 & 16 & 60 & 0.5 & 16 & 6 & 1 \\
12 & 20 & 25 & 55 & 0.5 & 13 & 6 & 0.5 \\
6 & 40 & 22 & 54 & 0.5 & 15 & 8 & 0.5 \\
12 & 40 & 29 & 55 & 0.5 & 10 & 5 & 0.5 \\
24 & 40 & 16 & 52 & 0.5 & 19 & 11 & 1.5 \\
1 & 80 & 100 & - & - & - & - & - \\
3 & 80 & 90 & 8 & - & 1 & - & - \\
4 & 80 & 67 & 31 & - & 2 & -
\end{tabular}

${ }^{a}$ Stirred autoclave reactions under self generated pressure at $180{ }^{\circ} \mathrm{C} ; \mathrm{HM}(\mathrm{Si} / \mathrm{Al}=10$, $4.0 \mathrm{~g})$, cyclohexane $(50 \mathrm{~mL})$, naphthalene $(1.28 \mathrm{~g} ; 10 \mathrm{mmol})$ and tert-amyl alcohol. ${ }^{b}$ See footnote $b$ to Table 2 . 
Table 6 shows that the reaction was faster with less tert-amyl alcohol (20 mmol) than with the larger quantities, especially $80 \mathrm{mmol}$, which gave a low conversion (33\%) and yield of $4(2 \%)$ after $4 \mathrm{~h}$. The general trend on increasing the reaction time was an increase in the conversion and yield of 4, but increases were rather small after $6 \mathrm{~h}$. Clearly, the majority of the reaction occurred within the first 6 to $12 \mathrm{~h}$, at least when 20 or 40 mmol tert-amyl alcohol was used.

As the conversion and yield of $\mathbf{4}$ were not improved very much by increasing the amount of zeolite, an attempt was made at multistaging the reaction. After each stage, the old zeolite was removed; the product mixture was concentrated; and fresh zeolite, tert-amyl alcohol and cyclohexane were added. Several experiments were conducted in which the quantity of tert-amyl alcohol was $20 \mathrm{mmol}$ for $10 \mathrm{mmol}$ of $\mathbf{1}$ and the reaction time was $1 \mathrm{~h}$ in each experiment. The first stage was equivalent to the normal $4 \mathrm{~g} / 10$ mmol reaction. The resulting product mixture was reacted again with fresh zeolite, additional tert-amyl alcohol $(20 \mathrm{mmol})$ and fresh solvent. Therefore, after two stages, $\mathrm{HM}(\mathrm{Si} / \mathrm{Al}=10 ; 8 \mathrm{~g})$ and tert-amyl alcohol $(40 \mathrm{mmol})$ had been reacted with the naphthalene $(10 \mathrm{mmol})$. This process was then repeated for third, fourth, fifth and sixth stages, such that catalyst (24 g) and tert-amyl alcohol $(120 \mathrm{mmol})$ were used in total, although in principle these materials could be recycled. The results obtained are given in Table 7 .

The results reported in Table 7 clearly indicated that both the conversion and yields of dialkylnaphthalenes 4-6 increased stage by stage. After the sixth stage, the yield of 4 and 5 were 35 and 20\%, respectively, while the yield of 6 was $2 \%$. 
Table 7 Multistaging tert-amylation of naphthalene $(\mathbf{1})$ over $\mathrm{HM}(\mathrm{Si} / \mathrm{Al}=10)$ in cyclohexane for $1 \mathrm{~h}$ according to Scheme $1^{a}$

\begin{tabular}{lllllll}
\hline Stage & \multicolumn{7}{c}{${\text { Yields }(\%)^{b}}^{b}$} \\
\cline { 2 - 8 } & $\mathbf{1}$ & $\mathbf{2}$ & $\mathbf{3}$ & $\mathbf{4}$ & $\mathbf{5}$ & $\mathbf{6}$ \\
\hline 1 & 40 & 49 & 0.5 & 5 & 4 & 0.5 \\
2 & 21 & 56 & 0.5 & 12 & 9 & 1 \\
3 & 13 & 55 & 0.5 & 19 & 11 & 1 \\
4 & 13 & 50 & 0.5 & 21 & 13 & 1 \\
5 & 5 & 45 & 0.5 & 30 & 17 & 2 \\
6 & 3 & 40 & - & 35 & 20 & 2
\end{tabular}

${ }^{a}$ Each stage is a $1 \mathrm{~h}$ stirred autoclave reaction under self generated pressure at $180{ }^{\circ} \mathrm{C}$; $\mathrm{HM}(\mathrm{Si} / \mathrm{Al}=10 ; 4.0 \mathrm{~g})$, cyclohexane $(50 \mathrm{~mL})$, naphthalene $(1.28 \mathrm{~g} ; 10 \mathrm{mmol})$, tert-amyl alcohol (1.76 g; $20 \mathrm{mmol})$. At the beginning of each stage, the old zeolite was removed by filtration and washed with acetone $(20 \mathrm{~mL})$; the combined filtrates were allowed to evaporate in air at atmospheric pressure for $6 \mathrm{~h}$ (to avoid losses of more volatile components such as naphthalene) before addition of fresh $\mathrm{HM}(\mathrm{Si} / \mathrm{Al}=10 ; 4.0 \mathrm{~g})$, fresh cyclohexane $(50 \mathrm{~mL})$ and fresh tert-amyl alcohol $(1.76 \mathrm{~g} ; 20 \mathrm{mmol}) .{ }^{b}$ See footnote $b$ to Table 2.

We have also attempted to vary the reaction time (6 or $12 \mathrm{~h})$ in the multistaging tert-amylation of naphthalene (1) over $\mathrm{HM}(\mathrm{Si} / \mathrm{Al}=10)$ in cyclohexane in an attempt to increase the yield of $\mathbf{4}$. However, the yield of $\mathbf{4 - 6}$ obtained was only $49 \%$ after four stages (Table 8).

Table 8 Multistaging tert-amylation of naphthalene (1) over $\mathrm{HM}(\mathrm{Si} / \mathrm{Al}=10)$ in cyclohexane for different times according to Scheme $1^{a}$

\begin{tabular}{llllllll}
\hline Stage & Time $(\mathrm{h})$ & \multicolumn{7}{c}{${\text { Yields }(\%)^{b}}^{b}$} \\
\cline { 3 - 8 } & & $\mathbf{1}$ & $\mathbf{2}$ & $\mathbf{3}$ & $\mathbf{4}$ & $\mathbf{5}$ & $\mathbf{6}$ \\
\hline 1 & 6 & 25 & 52 & 3 & 6 & 5 & 1 \\
2 & 12 & 11 & 57 & 1.5 & 17 & 12 & 1.5 \\
3 & 6 & 6 & 59 & 1 & 19 & 13 & 2 \\
4 & 12 & 2 & 48 & 0.5 & 27 & 19 & 3
\end{tabular}

${ }^{a}$ Each stage involved a stirred autoclave reaction under self-generated pressure at $180^{\circ} \mathrm{C}$; $\mathrm{HM}(\mathrm{Si} / \mathrm{Al}=10 ; 4.0 \mathrm{~g})$, cyclohexane $(50 \mathrm{~mL})$, naphthalene $(1.28 \mathrm{~g} ; 10 \mathrm{mmol}$, added at the first stage only), tert-amyl alcohol $(1.76 \mathrm{~g} ; 20 \mathrm{mmol})$ for the required time. At the beginning of each stage, the old zeolite was removed by filtration and washed with acetone $(20 \mathrm{~mL})$; the combined filtrates were allowed to evaporate in air at atmospheric pressure for $6 \mathrm{~h}$ before addition of fresh $\mathrm{HM}(\mathrm{Si} / \mathrm{Al}=10 ; 4.0 \mathrm{~g})$, fresh cyclohexane (50 $\mathrm{mL})$ and fresh tert-amyl alcohol $(1.76 \mathrm{~g} ; 20 \mathrm{mmol}){ }^{b}$ See footnote $b$ to Table 2. 
Our attention was next turned to studying the effect of reaction time and the quantity of tert-amyl alcohol in the multistaging tert-amylation of naphthalene. Two different sets of experiments were conducted in which the quantity of tert-amyl alcohol was varied (20 or $80 \mathrm{mmol}$ for $10 \mathrm{mmol}$ of $\mathbf{1}$ ). The first stage was equivalent to the normal $4 \mathrm{~g} / 10 \mathrm{mmol}$ reaction. The resulting product mixture was reacted again with fresh zeolite, additional tert-amyl alcohol (20 or $80 \mathrm{mmol})$ and fresh solvent. Therefore, after two stages, $\mathrm{HM}(\mathrm{Si} / \mathrm{Al}=10 ; 8 \mathrm{~g})$ and tert-amyl alcohol $(40$ or $160 \mathrm{mmol})$ had been reacted with the naphthalene $(1 ; 10 \mathrm{mmol})$. This process was then repeated for third, fourth and fifth stages, such that zeolite $(20 \mathrm{~g})$ and tert-amyl alcohol (100 or $400 \mathrm{mmol})$ were used in total. The results obtained are given in Table 9.

Table 9 Multistaging tert-amylation of naphthalene (1) over $\mathrm{HM}(\mathrm{Si} / \mathrm{Al}=10)$ in cyclohexane for $6 \mathrm{~h}$ according to Scheme $1^{a}$

\begin{tabular}{llllllll}
\hline Stage & $\begin{array}{l}\text { tert-Amyl alcohol } \\
(\mathrm{mmol})\end{array}$ & $\mathbf{1}$ & $\mathbf{2}$ & $\mathbf{3}$ & $\mathbf{4}$ & $\mathbf{5}$ & $\mathbf{6}$ \\
\hline 1 & 20 & 22 & 58 & 2 & 10 & 6 & 2 \\
2 & 20 & 11 & 55 & 1.5 & 18 & 13 & 1.5 \\
3 & 20 & 4 & 41 & 1.5 & 31 & 20 & 1 \\
4 & 20 & - & 36 & 1 & 38 & 24 & 1 \\
5 & 20 & - & 28 & 1 & 46 & 23 & 1 \\
1 & 80 & 66 & 31 & 1 & 2 & - & - \\
2 & 80 & 37 & 47 & 1 & 11 & 4 & 0.5 \\
3 & 80 & 25 & 46 & 3 & 16 & 7 & 0.5 \\
4 & 80 & 20 & 52 & 2.5 & 17 & 7 & 0.5 \\
5 & 80 & 10 & 47 & 0.5 & 30 & 12 & -
\end{tabular}

${ }^{a}$ Each stage was a $6 \mathrm{~h}$ stirred autoclave reaction under self-generated pressure at $180{ }^{\circ} \mathrm{C}$; $\mathrm{HM}(\mathrm{Si} / \mathrm{Al}=10 ; 4.0 \mathrm{~g})$, cyclohexane $(50 \mathrm{~mL})$, naphthalene $(1.28 \mathrm{~g} ; 10 \mathrm{mmol}$, added at the first stage only), tert-amyl alcohol. At the beginning of each stage, the old zeolite was removed by filtration and washed with acetone $(20 \mathrm{~mL})$; the combined filtrates were allowed to evaporate in air at atmospheric pressure for $6 \mathrm{~h}$ before addition of fresh HM $(\mathrm{Si} / \mathrm{Al}=10 ; 4.0 \mathrm{~g})$, fresh cyclohexane $(50 \mathrm{~mL})$ and fresh tert-amyl alcohol. ${ }^{b}$ See footnote $b$ to Table 2 .

The results reported in Table 9 clearly indicated that reactions with more alcohol proceeded more slowly than those with less. With $80 \mathrm{mmol}$ of alcohol in each stage the maximum conversion after five stages was $90 \%$ and the combined yields of 4-6 were $42 \%$, along with $47 \%$ of 2 and traces of $\mathbf{3}$. Higher yields and conversions were obtained 
when $20 \mathrm{mmol}$ of tert-amyl alcohol was used at each stage (combined yield of 4-6 was $70 \%$ after 5 stages), but the selectivity for production of $\mathbf{4}$ over $\mathbf{5}$ was better for reactions with $80 \mathrm{mmol}$ of alcohol (after five stages the yield of $\mathbf{4}$ was up to $30 \%$, with only $12 \%$ of 5 and virtually no 6 ).

We therefore attempted the multistaging tert-amylation of naphthalene $(10 \mathrm{mmol})$ in which tert-amyl alcohol $(50 \mathrm{~mL})$ was used as the solvent in order to improve the selectivity towards formation of $\mathbf{4}$ even further. The results obtained are given in Table 10.

It was found that using tert-amyl alcohol as the solvent resulted in a lower conversion $(25 \%)$ even after 6 stages but the reaction was more selective towards formation of 2,6-di-tert-amylnaphtahlene (4), giving a $4: 5$ ratio of 5. Also, no 2,6-di-tertbutylnaphtahlene (6) was formed under the conditions tried.

Table 10 Multistaging tert-amylation of naphthalene $(\mathbf{1})$ over $\mathrm{HM}(\mathrm{Si} / \mathrm{Al}=10)$ using tertamyl alcohol $(50 \mathrm{~mL})$ for $24 \mathrm{~h}$ according to Scheme $1^{a}$

\begin{tabular}{lllllll}
\hline Stage & \multicolumn{7}{c}{ Yields $(\%)^{b}$} \\
\cline { 2 - 7 } & $\mathbf{1}$ & $\mathbf{2}$ & $\mathbf{3}$ & $\mathbf{4}$ & $\mathbf{5}$ & $\mathbf{6}$ \\
\hline 1 & 97 & 2 & traces & 0.5 & traces & - \\
2 & 93 & 5 & traces & 1 & traces & - \\
3 & 81 & 14 & 0.5 & 3 & 1 & - \\
4 & 78 & 14 & 0.5 & 5 & 1 & - \\
5 & 76 & 15 & 0.5 & 5 & 1 & - \\
6 & 75 & 17 & 0.5 & 5 & 1 & -
\end{tabular}

${ }^{a}$ Each stage was a $24 \mathrm{~h}$ stirred autoclave reaction under self-generated pressure at 180 ${ }^{\circ} \mathrm{C} ; \mathrm{HM}(\mathrm{Si} / \mathrm{Al}=10 ; 4.0 \mathrm{~g})$, naphthalene $(1.28 \mathrm{~g} ; 10 \mathrm{mmol}$, added at the first stage only), tert-amyl alcohol $(50 \mathrm{~mL})$. At the beginning of each stage, the old zeolite was removed by filtration and washed with acetone $(20 \mathrm{~mL})$; the combined filtrates were allowed to evaporate in air at atmospheric pressure for $6 \mathrm{~h}$ before addition of fresh $\mathrm{HM}(\mathrm{Si} / \mathrm{Al}=10$; $4.0 \mathrm{~g})$ and fresh tert-amyl alcohol $(50 \mathrm{~mL}) .{ }^{b}$ See footnote $b$ to Table 2 .

The maximum yield of 2,6-dialkylnaphthalenes obtained thus so far was in the region of $70 \%$ and it seemed likely that this would not be much improved under the kinds of conditions tried. Therefore, our attention was turned to study the alkylation of naphthalene using different alcohols under conditions similar to those used with tert-amyl alcohol to see if any benefits could be achieved. 
Alkylations of naphthalene $(\mathbf{1} ; 10 \mathrm{mmol})$ were attempted at $180{ }^{\circ} \mathrm{C}$, using 2,2-dimethyl-1-propanol, 2,3-dimethyl-2-butanol and 3-methyl-2-butanol (20 mmol in each case $)$ over $\mathrm{HM}(\mathrm{Si} / \mathrm{Al}=10,4 \mathrm{~g})$ in cyclohexane $(50 \mathrm{~mL})$ under conditions similar to those used for the reaction depicted in Scheme 1.

For the primary alcohol (2,2-dimethyl-1-propanol) it was not surprising that no products were observed under these conditions. With 2,3-dimethyl-2-butanol as alkylating reagent, naphthalene conversion was $20 \%$. The major products were monoalkylated naphthalenes, namely 2-tert-amylnaphthalene (2; $0.5 \%)$ and 2-tert-butylnaphalene $(3 ; 5 \%)$ along with another mono-alkylated naphthalene, probably 2-(2,3-dimethyl-2-butyl)naphthalene (ca. 8\%). Dialkylated naphthalenes were produced in low yields (ca. $0.5 \%$ each) as a mixture of 2,6-di-tert-amylnaphthalene (4), 2-tert-amyl-6-tert-butylnaphthalene (5) and 2,6-di-tert-butylnaphthalene (6) along with another dialkylated naphthalene, probably containing a (2,3-dimethyl-2-butyl) group.

With 3-methyl-2-butanol as alkylating reagent, a naphthalene conversion of $80 \%$ was achieved. The yield of 2-tert-amylnaphthalene (2) was 62\%. 2,6-Di-tert-amylnaphthalene (4) and 2-tert-amyl-6-tert-butylnaphthalene (5) were also formed in $6 \%$ and $5 \%$ yields, respectively, along with traces of 2,6-di-tert-butylnaphthalene $(\mathbf{6} ; 0.5 \%)$. The tert-amylated products were presumably formed due to generation of tert-amyl cation from 3-methyl-2-butanol over the acidic zeolite (Scheme 3), while the tert-butylated products would be produced due to conversion of tert-amyl cation to tert-butyl cation over HM zeolite (Scheme 2).

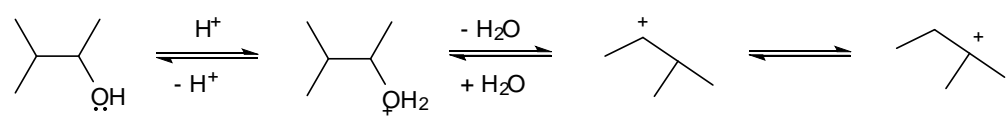

Scheme 3 Generation of tert-amyl cation form 3-methyl-2-butanol over an acidic zeolite

In an attempt to increase the yield of 2,6-dialkylnaphthalenes from the reaction with 3-methyl-2-butanol, the reaction was carried out in multistage mode using naphthalene $(1 ; 10 \mathrm{mmol})$, and for each stage the alcohol $(20 \mathrm{mmol}), \mathrm{HM}(\mathrm{Si} / \mathrm{Al}=10 ; 4$ g) and cyclohexane $(50 \mathrm{~mL})$ at $180{ }^{\circ} \mathrm{C}$ for $6 \mathrm{~h}$ (Table 11$)$. 
Table 11 Multistaging alkylation of naphthalene (1) using 3-methyl-2-butanol over HM $(\mathrm{Si} / \mathrm{Al}=10)$ in cyclohexane for $6 \mathrm{~h}^{a}$

\begin{tabular}{lllllll}
\hline Stage & \multicolumn{7}{c}{${\text { Yields }(\%)^{b}}^{b}$} & $\mathbf{3}$ & $\mathbf{6}$ \\
\cline { 2 - 7 } & $\mathbf{1}$ & $\mathbf{2}$ & $\mathbf{3}$ & $\mathbf{4}$ & $\mathbf{5}$ & 0.5 \\
1 & 20 & 62 & 2.5 & 6 & 8 & 1 \\
2 & 20 & 54 & 2.5 & 12 & 14 & 2 \\
3 & 4 & 56 & 2 & 20 & 19 & 2
\end{tabular}

${ }^{a}$ Each stage was a $6 \mathrm{~h}$ stirred autoclave reaction under self-generated pressure at $180{ }^{\circ} \mathrm{C}$ starting with naphthalene $(1.28 \mathrm{~g} ; 10 \mathrm{mmol}) ; \mathrm{HM}(\mathrm{Si} / \mathrm{Al}=10 ; 4.0 \mathrm{~g})$, cyclohexane (50 $\mathrm{mL})$, and 3-methyl-2-butanol $(1.76 \mathrm{~g} ; 20 \mathrm{mmol})$. At the beginning of each new stage, the old catalyst was removed by filtration and washed with acetone $(20 \mathrm{~mL})$; the combined filtrates were allowed to evaporate in air at atmospheric pressure for $6 \mathrm{~h}$ before addition of fresh $\mathrm{HM}(\mathrm{Si} / \mathrm{Al}=10 ; 4.0 \mathrm{~g})$, fresh cyclohexane $(50 \mathrm{~mL})$ and fresh alcohol $(1.76 \mathrm{~g} ; 20$ mmol). ${ }^{b}$ See footnote $b$ to Table 2 .

The results reported in Table 11 showed that the conversion was $80 \%$ after the first stage and increased to $100 \%$ after the fourth stage. The yield of 2-tert-amylnaphthalene (2) was reduced from 62 to $45 \%$ after the fourth stage. The maximum yield of 2,6-dialkylnaphthalenes was 53\%, of which the yield of 4 was $32 \%$. Also, after the fourth stage, 2,6-dialkylnaphthalenes 5 and $\mathbf{6}$ were formed in 19 and 2\% yields, respectively.

In order to check on the possibility of reuse of the zeolite, a single reaction of $\mathbf{1}$ (10 mmol) was carried out using tert-amyl alcohol $(20 \mathrm{mmol})$, and the zeolite was recovered following extraction of the products and was then regenerated by heating overnight in air in an oven set at $550{ }^{\circ} \mathrm{C}$. The regenerated zeolite was then reused in an identical reaction. This process was repeated several times with the same batch of zeolite. The yield and selectivity of each reaction are recorded in Table 12. It can be seen that the zeolite could be effectively recycled, while retaining substantial activity and selectivity even after using six times. 
Table 12 Efficiency of recycled calcined $\mathrm{HM}(\mathrm{Si} / \mathrm{Al}=10)$ zeolite in tert-amylation of naphthalene (1) in cyclohexane according to Scheme $1^{a}$

\begin{tabular}{|c|c|c|c|c|c|c|}
\hline \multirow[t]{2}{*}{ Run } & \multicolumn{6}{|c|}{ Yields $(\%)^{b}$} \\
\hline & 1 & 2 & 3 & 4 & 5 & 6 \\
\hline 1 & 22 & 58 & 2 & 10 & 6 & 2 \\
\hline 2 & 21 & 59 & 2 & 9 & 5 & 3 \\
\hline 3 & 20 & 59 & 2 & 10 & 6 & 2 \\
\hline 4 & 21 & 57 & 3 & 11 & 5 & 2 \\
\hline 5 & 20 & 58 & 2 & 10 & 5 & 2 \\
\hline 6 & 23 & 57 & 2 & 9 & 4 & 3 \\
\hline
\end{tabular}

${ }^{a}$ Stirred autoclave reaction for $6 \mathrm{~h}$ under self generated pressure at $180{ }^{\circ} \mathrm{C} ; \mathrm{HM}(\mathrm{Si} / \mathrm{Al}=$ $10,4.0 \mathrm{~g})$, cyclohexane $(50 \mathrm{~mL})$, naphthalene $(1.28 \mathrm{~g} ; 10 \mathrm{mmol})$ and tert-amyl alcohol $(1.76 \mathrm{~g} ; 20 \mathrm{mmol})$. The reaction was scaled down after the first use of zeolite. ${ }^{b}$ See footnote $b$ to Table 2 .

\section{Conclusions}

The autoclave reaction of tert-amyl alcohol with naphthalene at $180^{\circ} \mathrm{C}$ in the presence of sufficient $\mathrm{HM}(\mathrm{Si} / \mathrm{Al}=10)$ zeolite provides a convenient method for the synthesis of 2,6-dialkylnaphthalenes selectively in high yields, with no 2,7-isomers detected. In addition to 2,6-di-tert-amylnaphthalene, however, a significant quantity of 2-tert-amyl-6tert-butylnaphthalene is also formed and is difficult to separate from the major product. Heating easily regenerates the zeolite, which can be reused to give results similar to those of a fresh sample.

The two major products of these reactions could both have commercial significance. 2-tert-Amylnaphthalene is a known lubricant, ${ }^{51}$ while 2,6-di-tertamylnaphthalene, a novel compound, could in principle be cracked ${ }^{49}$ to give DMN, a key intermediate in the production of PEN. Current methods for production of DMN involve multiple steps (at least one of which is low yielding), difficult and tedious separations of isomers, and isomerisation/recycling of by-products. Therefore, the present method offers great potential for improving the "greenness" and commercial viability of the production of PEN, although it would probably need to be converted into a continuous process. 


\section{Experimental}

\section{Materials}

Chemicals and solvents were purchased from Aldrich Chemical Company and used without further purification. H-Mordenite $(\mathrm{HM} ; \mathrm{Si} / \mathrm{Al}=10)$ zeolite was purchased from Zeolyst International and freshly calcined at $550{ }^{\circ} \mathrm{C}$ for a minimum of $6 \mathrm{~h}$ prior to use.

\section{Analysis and characterization of the products}

Product mixtures from the tert-amylation reactions of naphthalene were subjected to gas chromatography using a Hewlett Packard 5890 Series II Gas Chromatograph fitted with a Zebron ZB-5 (5\% phenyl-95\% dimethylpolysiloxane), 0.32mm ID) $30 \mathrm{~m}$ length column. The GC conditions used for analysis were: $170{ }^{\circ} \mathrm{C}$ for $0.5 \mathrm{~min}$, ramped to $300{ }^{\circ} \mathrm{C}$ at $4{ }^{\circ} \mathrm{C} / \mathrm{min}$. The injection temperature and detection temperature were each $295{ }^{\circ} \mathrm{C}$. Hexadecane was used as a GC standard. The structure of the novel compound 2,6-di-tertamylnaphtalene (4) was confirmed by ${ }^{1} \mathrm{H}$ and ${ }^{13} \mathrm{C}$ NMR spectra, mass spectral analysis and X-ray crystal structure (Figure 1).

Melting points were determined by the open capillary method using a Gallenkamp melting point apparatus and are reported uncorrected. ${ }^{1} \mathrm{H}$ and ${ }^{13} \mathrm{C}$ NMR spectra were recorded on a Bruker AV400 spectrometer operating at $400 \mathrm{MHz}$ for ${ }^{1} \mathrm{H}$ and $100 \mathrm{MHz}$ for ${ }^{13} \mathrm{C}$ measurements. Chemical shifts $\delta$ are reported in parts per million (ppm) relative to TMS and coupling constants $J$ are in $\mathrm{Hz} .{ }^{13} \mathrm{C}$ multiplicities were revealed by DEPT signals. Assignments of signals are based on integration values, coupling patterns and expected chemical shift values. Mass spectra were recorded on a GCT premier-EI mass spectrometer.

The X-ray single-crystal diffraction data were collected on a Nonius Kappa CCD diffractometer using graphite-monochromated $\mathrm{Mo}_{\alpha},(\lambda=0.71073 \AA)$ radiation. The structure of 4 was solved by direct methods using SHELXS-96 $6^{52}$ and refined with all data on $\mathrm{F}^{2}$ full-matrix least squares using SHELXL-97. ${ }^{53}$ Full crystallographic data have been deposited with the CCDC, reference number 827589, and can be obtained free of charge via http://www.ccdc.ac.uk/data_request/cif. 


\section{Typical experimental procedure for the tert-amylation of naphthalene using tert-amyl alcohol over HM zeolite}

Quantities are recorded in the footnotes to the appropriate tables. All reactions were carried out in a $100 \mathrm{ml}$ Teflon-lined Parr autoclave, fitted with a thermocouple and gauge block assembly. To the Teflon liner of the autoclave were added a magnetic bar, naphthalene, tert-amyl alchol and solvent. The mixture was allowed to stir until all naphthalene had dissolved ( $c$. $5 \mathrm{~min}$ ) and then HM zeolite was added. The Teflon liner was transferred into the stainless steel autoclave, which was sealed and heated for the appropriate reaction time and temperature, with stirring, under self-generated pressure. In some experiments the system was artificially pressurised up to 500 psi with nitrogen gas prior to heating. After the given reaction time, the heating device was removed and the autoclave was allowed to cool to room temperature $(c a .2 \mathrm{~h})$. The contents were removed and the apparatus was then washed thoroughly with acetone. The acetone washings were combined with the original contents and the catalyst was removed by filtration. The solid was thoroughly extracted with further acetone and the combined mother liquors were concentrated under reduced pressure. The product mixture was analysed by quantitative gas chromatography using hexadecane as the GC standard and the yields were calculated.

\section{Preparation of a mixture of 2,6-dialkylnaphthalenes by multistaging the reaction}

A mixture of $\mathrm{HM}(\mathrm{Si} / \mathrm{Al}=10 ; 4.0 \mathrm{~g})$, cyclohexane $(50 \mathrm{~mL})$, naphthalene $(1.28 \mathrm{~g} ; 10$ mmol, added at the first stage only) and tert-amyl alcohol (1.76 g; $20 \mathrm{mmol})$ was heated at $180{ }^{\circ} \mathrm{C}$ for $6 \mathrm{~h}$ in an autoclave. The mixture was allowed to cool to room temperature and the product mixture was concentrated (by allowing the volatile components to evaporate over 6 hours $)$ and fresh $\mathrm{HM}(\mathrm{Si} / \mathrm{Al}=10 ; 4.0 \mathrm{~g})$, fresh cyclohexane $(50 \mathrm{~mL})$ and fresh tert-amyl alcohol (1.76 g; $20 \mathrm{mmol})$ were added. The reaction was then allowed to proceed again under the same conditions. The crude product obtained after multistaging the reaction five times (Table 9) was a mixture of a white crystalline solid and an oily material $(2.41 \mathrm{~g})$, which were separated by filtration and the solid was washed with ethanol. The GC of oil and washing $(0.70 \mathrm{~g})$ indicated the presence of 2-tert-amylnaphthalene (2) as the major component along with traces of the other compounds. The NMR analysis of the solid $(1.71 \mathrm{~g})$ showed the presence of 
2,6-di-tert-amylnaphthalene (4) along with 2-tert-amyl-6-tert-butylnaphthalene (5) and 2,6-di-tert-butylnaphthalene (6) in the ratio of $c a$. 12:5:1. Crystallisation of this solid (ca. $0.1 \mathrm{~g}$ ) from ethanol provided colourless crystals of $\mathbf{4}$ that still contained a significant quantity of $\mathbf{5}$ but which could be analysed by X-ray crystallography to confirm the structure as 4 (Figure 1).

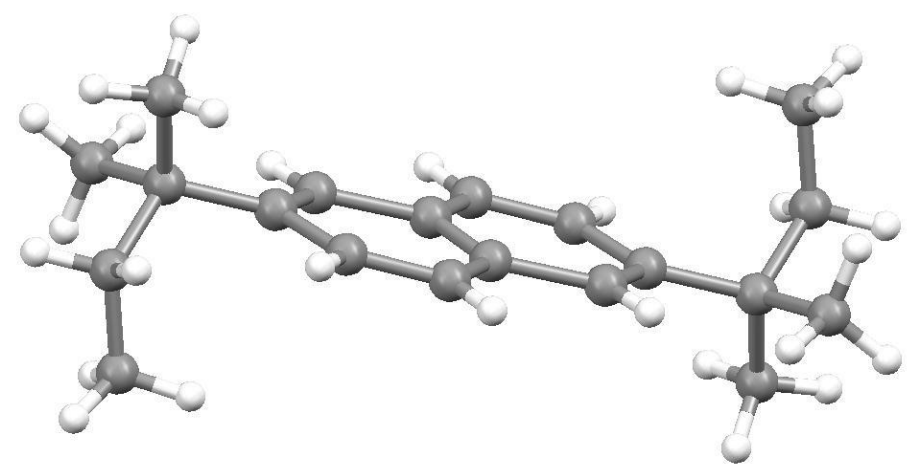

Figure 1 X-Ray crystal structure for 2,6-di-tert-amylnaphthalene (4)

\section{GC MS Analytical data for the mixture of 2,6-di-alkylnaphthalenes 4-6}

Yield: $1.71 \mathrm{~g}$ starting from naphthalene (1.28 g; $10 \mathrm{mmol})$. EI-MS (\%) 4: $268\left(\mathrm{M}^{+}, 35\right)$, 253 (10), 239 (100), 224 (5), 210 (30), 195 (20), 167 (10), 141 (7), 128 (2), 71 (3); EI-MS

(\%) 5: $254\left(\mathrm{M}^{+}, 19\right), 239$ (10), 225 (100), 210 (10), 195 (10), 181 (5), 167 (7), 141 (7), 128 (2), 57 (2); EI-MS (\%) 6: 240 (M+ , 29), 225 (100), 218 (5), 210 (7), 195 (7), 179 (2), 165 (6), 152 (5), 141 (5), 129 (2), 115 (1), 91 (3), 77 (2), 57 (2).

\section{Analytical data for 2,6-di-tert-amylnaphthalene (4), deduced from the spectra of the} mixture

${ }^{1} \mathrm{H}$ NMR (400 MHz, $\left.\mathrm{CDCl}_{3}\right): \delta 7.80(\mathrm{~d}, J=8.6 \mathrm{~Hz}, 2 \mathrm{H}, \mathrm{H}-4$ and $\mathrm{H}-8), 7.72(\mathrm{~d}, J=1.7$ $\mathrm{Hz}, 2 \mathrm{H}, \mathrm{H}-1$ and H-5), 7.52 (dd, $J=1.7,8.6 \mathrm{~Hz}, 2 \mathrm{H}, \mathrm{H}-3$ and H-7), 1.78 (q, $J=7.5 \mathrm{~Hz}$, $4 \mathrm{H}, 2 \mathrm{CH}_{2} \mathrm{CH}_{3}$ ), 1.42 (s, $12 \mathrm{H}, 4 \mathrm{CH}_{3}$ ), 0.73 (t, $\left.J=7.5 \mathrm{~Hz}, 6 \mathrm{H}, 2 \mathrm{CH}_{2} \mathrm{CH}_{3}\right) ;{ }^{13} \mathrm{C} \mathrm{NMR}$ $\left(100 \mathrm{MHz}, \mathrm{CDCl}_{3}\right.$ ): $\delta 146.6$ (s, C-2 and C-6), 131.9 (s, C-4a and C-8a), 127.9 (d, C-4 and C-8), 125.3 (d, C-3 and C-7), 124.0 (d, C-1 and C-5), 38.4 [s, $\left.C\left(\mathrm{CH}_{3}\right)_{2}\right], 37.0$ (t, 
$\mathrm{CH}_{2} \mathrm{CH}_{3}$ ), 29.0 [q, $\mathrm{C}\left(\mathrm{CH}_{3}\right)_{2}$ ], 9.6 (q, $\left.\mathrm{CH}_{2} \mathrm{CH}_{3}\right)$; HRMS (EI): calcd for $\mathrm{C}_{20} \mathrm{H}_{28}\left[\mathrm{M}^{+}\right]$: 268.2191; found: 268.2184 .

Crystal data for 4: colourless, $\mathrm{C}_{20} \mathrm{H}_{28}, T=15(2) \mathrm{k}$, monoclinic, space group $P 21 / \mathrm{n}, a=$

6.7860(18) $\AA, b=12.584(2) \AA, c=9.896(3) \AA, \alpha=90^{\circ}, \beta=94.038(8)^{\circ}, \gamma=90^{\circ}, 1413$ reflections collected, 748 independent reflections, $R=0.1100, w R=0.2877, R($ int $)=$ 0.0949. CCDC 827589.

\section{Acknowledgments}

We thank Cardiff University and the Iraqi Government for financial support. We also thank Dr B. M. Kariuki for the X-ray crystal structure.

\section{Notes and references}

1 S.-B. Pu and T. Inui, Zeolites, 1996, 17, 334-339.

2 E. Armengol, A. Corma, H. García and J. Primo, Appl. Catal. A: Gen., 1997, 149, 411-423.

3 R. Gläser, R. Li, M. Hunger, S. Ernst and J. Weitkamp, Catal. Lett., 1998, 50, 141-148.

4 C. He, Z. Liu, F. Fajula and P. Moreau, Chem. Commun., 1998, 1999-2000.

5 I. Ferino, R. Monaci, E. Rombi, V. Solinas, P. Magnoux and M. Guisnet, Appl. Catal. A: Gen., 1999, 183, 303-316.

6 P. Moreau, C. He, Z. Liu and F. Fajula, J. Mol. Catal. A: Chem., 2001, 168, 105114.

7 R. P. Marathe, S. Mayadevi, S. A. Pardhy, S. M. Sabne and S. Sivasanker, J. Mol. Catal. A: Chem., 2002, 181, 201-206.

8 R. Millini, F. Frigerio, G. Bellussi, G. Pazzuconi, C. Perego, P. Pallesel and U. Romano, J. Catal., 2003, 217, 298-309.

9 Ch. Subrahmanyam, B. Viswanathan and T. K. Varadaraj, J. Mol. Catal. A: Chem., 2005, 226, 155-163.

10 Y. Sugi, H. Maekawa, H. Naiki, K. Komura and Y. Kubota, Bull. Chem. Soc. Jpn., 2008, 81, 1166-1174. 
11 Y. Wang, L. Xu, Z. Yu, X. Zhang and Z. Liu, Catal. Commun., 2008, 9, 19821986.

12 Y. Sugi, H. Maekawa, Y. Hasegawa, H. Naiki, K. Komura and Y. Kubota, Catal. Today, 2008, 132, 27-37.

13 T. Shibata, H. Kawagoe, H. Naiki, K. Komura, Y. Kubota and Y. Sugi, J. Mol. Catal. A: Chem., 2009, 297, 80-85.

14 C. Bouvier, W. Buijs, J. Gascon, F. Kapteijn, B. C. Gagea, P. A. Jacobs and J. A. Martens, J. Catal., 2010, 270, 60-66.

15 K. Vahteristo, K.-M. Sahala, and S. Koskimies, Ind. Eng. Chem. Res., 2010, 49, 4018-4025.

16 G. A. Olah and J. A. Olah, J. Am. Chem. Soc., 1976, 98, 1839-1842.

17 M. Butters, in Solid Supports and Catalysts in Organic Synthesis, ed. K. Smith, Ellis Harwood, Chichester, 1992, pp. 130.

18 L. Delaude, P. Laszlo and K. Smith, Acc. Chem. Res., 1993, 26, 607-613.

19 Catalysis of Organic Reactions using Supported Inorganic Reagents, ed. J. H. Clark, VCH, New York, 1994.

20 J. H. Clark, Acc. Chem. Res., 2002, 35, 791-797.

21 K. Smith and G. A. El-Hiti, Curr. Org. Synth., 2004, 1, 253-274.

22 K. Smith and G. A. El-Hiti, Green Chem., 2011, 13, 1579-1608.

23 K. Smith, A. Musson and G. A. DeBoos, J. Org. Chem., 1998, 63, 8448-8454.

24 K. Smith, A. Musson and G. A. DeBoos, Chem. Commun., 1996, 469-470.

25 K. Smith, T. Gibbins, R.W. Millar and R. P. Claridge, J. Chem. Soc. Perkin Trans. 1, 2000, 2753-2758.

26 K. Smith, S. Almeer and S. T. Black, Chem. Commun., 2000, 1571-1572.

27 K. Smith, S. Almeer and C. Peters, Chem. Commun., 2001, 2748-2749.

28 K. Smith, M. D. Ajarim and G. A. El-Hiti, Catal. Lett., 2010, 134, 270-278.

29 K. Smith, G. H. El-Hiti, M. E. H. Hammond, D. Bahzad, Z. Li and C. Siquet, J. Chem. Soc. Perkin Trans. 1, 2000, 2745-2752.

30 K. Smith, M. Butters, W. E. Paget, D. Goubet, E. Fromentin and B. Nay, Green Chem., 1999, 1, 83-90. 
31 K. Smith, G. M. Ewart and K. R. Randles, J. Chem. Soc., Perkin Trans. 1, 1997, 1085-1086.

32 K. Smith, Z. Zhenhua and P. K. G. Hodgson, J. Mol. Catal. A. Chem., 1998, 134, 121-128.

33 K. Smith, G. A. El-Hiti, A. J. Jayne and M. Butters, Org. Biomol. Chem., 2003, 1, 1560-1564.

34 K. Smith, S. D. Roberts and G. A. El-Hiti, Org. Biomol. Chem., 2003, 1, 15521559.

35 K. Smith and S. D. Roberts, Catal. Today, 2000, 60, 227-233.

36 D. Fraenkel, M. Cherniavsky, B. Ittah and M. Levy, J. Catal., 1986, 101, 273-283

37 M. G. Cutrufello, I. Ferino, R. Monaci, E. Rombi, V. Solinas, P. Magnoux and M. Guisnet, Appl. Catal. A: Gen., 2003, 241, 91-111.

38 R. Brzozowski and W. Tęcza, Appl. Catal. A: Gen., 1998, 166, 21-27.

39 A. Katayama, M. Toba, G. Takeuchi, F. Mizukami, S. I. Niwa and S. Mitamura, J. Chem. Soc. Chem. Commun., 1991, 39-40.

40 A. D. Schmitz and C. S. Song, Catal. Today, 1996, 31, 195-199.

41 A. D. Schmitz and C. S. Song, Catal. Lett., 1996, 40, 59-65.

42 J. H. Kim, Y. Sugi, T.Matsuzaki, T.Hanaoka, Y.Kubota, X. Tu, M. Matsumoto, S. Nakata, A. Kato, G. Seo and C. Pak, Appl. Catal. A: Gen., 1995, 131, 15-32.

43 P. Moreau, A. Finiels, P. Geneste and J. Solofo, J. Catal., 1992, 136, 487-492.

44 P. P. B. Notte, G. M. J. L. Poncelet, M. J. H. Remy, P. E. M. G. Lardinois and M. J. M. van Hoecke, Eur. Pat., 0,528,096, 1993.

45 P. Moreau, A. Finiels, P. Geneste, F. Moreau and J. Solofo, J. Org. Chem., 1992, 57, 5040-5041.

46 Z. Liu, P. Moreau and F. Fajula, Chem. Commun., 1996, 2653-2654.

47 Z. Liu, P. Moreau and F. Fajula, Appl. Catal. A: Gen., 1997, 159, 305-316.

48 R. G. Larsen, R.E. Thorpe and F.A. Armfield, Ind. Eng. Chem., 1942, 34, 183-193

49 B. S. Greensfelder, H. H. Voge and G. M. Good, Ind. Eng. Chem., 1945, 37, 1168-1176. 
50 T. Koyama, Y. Hayashi, H. Horie, S. Kawauchi, A. Matsumoto, Y. Iwase, Y. Sakamoto, A. Miyaji, K. Motokura and T. Baba, Phys. Chem. Chem. Phys., 2010, $12,2541-2554$.

51 T. Yoshida and H. Watanabe, US Pat., 4,737,297, 1988.

52 G. M. Sheldrick, Acta Crystallogr. Sect. A., 1990, 46, 467-473.

53 G. M. Sheldrick, SHELXS-97, Program for Crystal Structure Refinement, Universität Göttingen, 1997. 